\title{
Characterization of Antibodies That Inhibit HIV gp I 20 Antigen Processing and Presentation
}

\author{
Maria Luisa Visciano* ${ }^{* 1}$, Michael Tuen ${ }^{1}$, Peter C Chien Jr ${ }^{1}$, Sandra Cohen ${ }^{1}$, \\ Pei-de Chen ${ }^{1}$, James Robinson'2, Yuxian $\mathrm{He}^{3}$, Abraham Pinter ${ }^{3}$, \\ Miroslaw K Gorny ${ }^{1}$ and Catarina E Hioe ${ }^{1}$
}

\begin{abstract}
Address: ${ }^{1}$ Department of Pathology, New York University School of Medicine, and Veterans Affairs New York Harbor Healthcare System, 423 East 23rd St. Room 18-124N, New York, New York 10010, USA, ²Department of Pediatrics, Tulane University Medical Center, 1430 Tulane Avenue, New Orleans, LA 70012, USA and ${ }^{3}$ Laboratory of Retroviral Biology, Public Health Research Institute, 225 Warren St., Newark, NJ 07103, USA

Email: Maria Luisa Visciano* - mlvisciano@yahoo.com

* Corresponding author $¥$ Presenting author
\end{abstract}

from 2005 International Meeting of The Institute of Human Virology

Baltimore, USA, 29 August - 2 September 2005

Published: 8 December 2005

Retrovirology 2005, 2(SuppI I):PI00 doi:I0.I I86/1742-4690-2-SI-PI00

\section{Background}

The capacity of $A b$ to alter antigen uptake and processing resulting in enhanced or suppressed antigen presentation has been demonstrated with a number of antigens, including tetanus toxoid, $\beta$-galactoside, apo-cytochrome c, and HIV-1 envelope glycoproteins [1-6]. In the case of HIV-1, the inhibitory activity is correlated with the serum $\mathrm{Ab}$ titers to the CD4-binding site (CD4bs) of gp120 [7]. In fact, by screening a panel of human anti-gp120 mAb, we ascertained that this inhibitory activity is mediated by $\mathrm{Ab}$ to the CD4bs; Ab to V2, V3, C2, or C5 did not exhibit such effect [1]. In previous studies only high affinity anti$\mathrm{CD} 4 \mathrm{bs} \mathrm{mAb}$ were examined; these mAb completely block MHC class II presentation of gp120 antigens $[1,2]$. However, it is not known if all anti-CD4bs Ab equally mediate such a strong inhibition. Since gp120/mAb complex formation was shown to be critical for anti-CD4bs mAb to block gp120 processing and presentation [1,2], we postulated that the $\mathrm{Ab}$ affinity could be a key determinant for their suppressive activity.

\section{Material and methods}

In the present study we selected a panel of six anti-CD4bs $\mathrm{mAb}$ with different relative affinities for gp120, and examined their ability to suppress gp 120 presentation to CD4 $\mathrm{T}$ cells. In addition, we tested $\mathrm{CD} 4 \mathrm{i} \mathrm{mAb}$ binding to the chemokine-receptor-binding site that, similar to antiCD4bs mAb, were previously reported to render gp 120 more resistant to degradative enzymes [7]. For comparison, a mAb specific for a conformation-dependent epitope outside the receptor binding sites and a relatively high affinity anti-V3 mAb were also tested. The ability of each of these mAb to suppress class II antigen presentation to gp120-specific CD4 T cells was correlated with the $\mathrm{mAb}$ affinity for gp120. The uptake of gp 120 by APC was also evaluated in the presence of these mAb. Furthermore, we measured the stability of the mAb-gp120 interaction at acidic $\mathrm{pH}$ representing the endolysosomal environment in APC and quantified the effect of the mAb on the rate of gp120 proteolytic processing by lysosomal enzymes in vitro.

\section{Results}

Anti-CD4bs antibodies that completely obstruct gp120 presentation exhibit three common properties: relatively high affinity for gp120, acid stable interaction with gp120, and the capacity to slow the kinetics of gp120 proteolytic processing. None of these antibodies prevents gp120 internalization into APC.

\section{Conclusion}

The present studies demonstrate that poorly neutralizing anti-CD4bs Ab produced by chronically HIV-1 infected patients prevent the stimulation of gp120-specific CD4 T cell responses. These $\mathrm{Ab}$ form relatively stable high-affinity immune complexes, which are resistant to proteolytic processing by lysosomal enzymes. The presence of such $\mathrm{Ab}$ in sera of HIV-1-infected patients may contribute to the dearth of helper CD4 T responses to the virus envelope antigens and consequently weaken the anti-viral immu- 
nity necessary to control the chronic HIV infection and disease.

Publish with Bio Med Central and every scientist can read your work free of charge

"BioMed Central will be the most significant development for disseminating the results of biomedical research in our lifetime. " Sir Paul Nurse, Cancer Research UK

Your research papers will be:

- available free of charge to the entire biomedical community

- peer reviewed and published immediately upon acceptance

- cited in PubMed and archived on PubMed Central

- yours - you keep the copyright

Submit your manuscript here:

http://www.biomedcentral.com/info/publishing_adv.asp 